\title{
NEW FINDINGS NOTES OF THE PARASITIC NEMATODES OF TERRESTRIAL INVERTEBRATES IN VIET NAM
}

\author{
Pham Van Luc ${ }^{*}$ \\ Vietnam Natural Museum, Vietnamese Academy of Science and Technology \\ Nguyen Vu Thanh \\ Institute of Ecology and Biological Resources, \\ Vietnamese Academy of Science and Technology \\ Spiridonov S.E. \\ Center of parasitology, Severtsov's Institute of Ecology and Evolution, \\ Russian academy of Sciences, Moscow, Russia
}

Received 10 March 2008

\begin{abstract}
First results of the parasitological survey of Vietnamese terrestrial invertebrates performed in 2007 demonstrate extreme diversity of nematodes parasitic in these animals. The most interesting new findings are nematodes of four superfamilies: Drilonematoidea, Thelastomatoidea, Rhabditoidea and Ransomnematoidea. Further progress was achieved in last three years in the studies of Drilonematoidea nematodes - coelomic parasites of earthworms. One new genus and several new species were discovered in large megascolecids collected in Bac Bo (Tam Dao) and Nam Bo (Bidoup - Nui Ba N.P.). Passalidae beetles are colonial coleopterans inhabiting rotten wood in tropical forests throughout tropics, and are known as characteristic hosts of one taxon of parasitic nematodes - family Hystrignathidae. The nematodes of this family were reported for the first time from Viet Nam in 2007. The fauna of parasitic nematodes of terrestrial mollusks is also diverse in Viet Nam. In addition to the new angiostomatids described in 2005 new Angiostoma species with unusual morphology was discovered in Cat Tien National Park. Nematodes of the family Hethidae were discovered in Vietnamese diplopods in 1997 but not identified up to species level. Examination of Heth specimens under light microscope and scanning electron microscope demonstrate prominent morphological differences between three samples from different areas in Viet Nam. Additional studies are needed to reveal the relationships of parasitic nematodes of terrestrial invertebrates found in Vietnam in 2007 and publish valid descriptions of these new taxa.
\end{abstract}

Keywords: Parasitic nematodes, Drilonematoidea, Thelastomatoidea, Rhabditoidea, Ransomnematoidea, terrestrial invertebrtes, Vietnam.

\footnotetext{
* Corresponding author e-mail: lucvp@ vast.ac.vn
} 


\section{MATERIAL AND METHODS}

Studies of parasitic nematodes in invertebrates of Viet Nam were started since 1986-1987, thanks to the support of Prof. Thai Tran Bai from Hanoi Pedagogical University. Since then numerous samples were collected during field trips in different provinces of the country (Cat Tien National park, Bidoup - Nui Ba National Park, Tam Dao and Sin Ho, lai Chau and Dien Bien Phu). At present, fauna of Vietnamese earthworms comprises of 29 species, with 28 species described by joint efforts of Vietnamese-Russian team.

Phylogenetic analysis based on the 18S rDNA was used to define the relationships of these two species of nematodes representing two families of Drilonematoidea (Ungellidae and Homungellidae, correspondingly). Sequences of D2D3 expansion segment of LSU rDNA of these nematodes were obtained and analyzed.

\section{RESULT}

\subsection{Studies in nematodes of the superfamily Drilonematoidea}

The nematodes of the superfamily Drilonematoidea are highly specialized parasites of earthworms, inhabiting coelomic cavity of the host. Studies in Drilonematoidea of Viet Nam were started in 1986-1987.

Since then numerous samples were collected during field trips in different provinces of the country. Earhworm fauna of Viet Nam is characterized by the prevalence of pheretimoid oligochaetes, which are also the most preferred hosts for Drilonematoidea nematodes. Up to date, drilonematid fauna of Vietnamese earthworms comprises of 29 species, with 28 species described by joint efforts of Vietnamese-Russian team. Between recent contributions to this field we would like to mention the description of two species of these nematodes: Siconema ovispicatum Spiridonov, Ivanova et Pham, 2007 from Amynhas robustus collected in Cuc Phuong National Park and Perodira minuta Spiridonov, Ivanova et Pham, 2007 from Pheretima hawayana collected in Ba Vi National Park (Spiridonov et al., 2007). Phylogenetic analysis based on the 18S rDNA was used to define the relationships of these two species of nematodes representing two families of Drilonematoidea (Ungellidae and Homungellidae, correspondingly). It was shown that both familes are phylogenetically related to the group of free-living cephalobid genera (Acrobeles, Cephalobus, Zeldia etc.). Another new finding of Drilonematoidea nematodes is the discovery of the new genus of the subfamily Ungellinae in Amynthas robustus from Tam Dao (Ivanova, Pham Van Luc, in press). It is the first finding of the Ungellinae in Viet Nam and the second in Australasia. The new genus is differentiated from the rest of Ungellidae by the presence of single strongly developed cephalic hook. In this respect it reminds the genus Homungella from another family Homungellidae. Still all the main features of Ungellinae can be found in newly erected genus, like presence of copulatory apparatus from spicules and gubernaculums, characteristic structure of anterior end of pharynx etc. Several new findings are still waiting for descriptions. E.g. several ungellid species were found in the earthworms of Bidoup-Nui Ba National Park, including Siconema rodericensis, found before only in Pheretima rodericensis near An Khe in Gia Lai province and Siconema laticaudatum, originally described from Amynthas leucocircus from Ba Vi National Park in Bac Bo. Another new species of ungellids of the genus Siconema was found in Bidoup - Nui Ba and studied under scanning electron microscope (Fig. 1, B). Very unusual suckers (fimbriate organs) in the shape of groove on the ventral margin of the inflated posterior part of the tail region let us to suppose that these nematodes are representing new species of Siconema. Previously described Drlonematoidea were also found during the field surveys of 2005-2007. E.g. Synoecnema hirsutum was reported from Pheretima postuma in Tu Liem, Ha Noi (Fig. 1, A) and $S$. ovispicatum was found in still unidentified earthworm in Cat Tien National Park. 

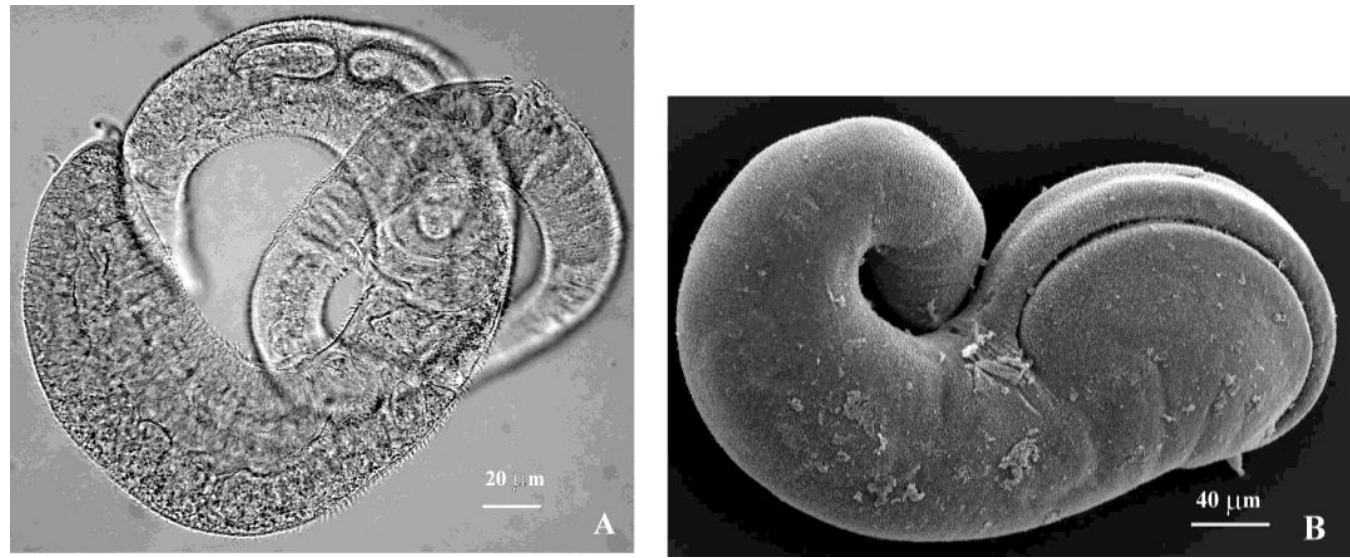

Fig. 1: Drilonematoidea nematodes from Vietnamese earthworms. A: female of Synoecnema hirsutum from Pheretima postuma, Tu Liem, Ha Noi, scale $20 \mu \mathrm{m}$; B: female of Siconema sp. from unidentified earthworm, Bidoup-Nui Ba, scale $40 \mu \mathrm{m}$.

\subsection{Studies in nematodes of the superfamily Thelastomatoidea}

The nematodes of the superfamily Thelastomatoidea are common inhabitants of hind gut (colon) of some invertebrate hosts. Several groups of arthropods like cockroaches, mole-crickets and diplopod millipedes are characteristic hosts for these nematodes, but these can be also found in earthworms and even Chelicerata. Recent studies in Bidoup - Nui Ba National Park revealed the presence of the Hystrignathidae nematodes in the posterior part of intestine of Passalidae beetles. These tropical beetles live as colonial insects in the rotten trunks of the wood in tropical forests: both imaginal and larval stages inhabit the tunnels of the same trunk. Heavy infestation of Vietnamese Passalidae with hystrignathid nematodes was found also near Sin Ho in Lai Chau province of Bac Bo in November 2007. The nematodes from Bidoup-Nui Ba were examined under SEM. All the characteristic features of hystrignathid morphology were observed (Fig. 2, A-C). Morphological features of anterior end support the identification of Vietnamese hystrignathids as members of Hystrignathus genus (Skrjabin et al., 1966). Light-microscopic examination of the male tail terminus revealed the presence of unusual anchor-like mucro. Such structure was described only once for Hystrignathus rigidus from USA (Leidy, 1850). Further studies are needed to define the relationships between Vietnamese hystrignathids and forms described from Neotropical Region (USA, Brasilia).

\subsection{Studies in nematodes of the superfamily Rhabditoidea}

First report of new taxa of the nematodes of the family Angistomatidae (Pham et al., 2005) contained descriptions of new genus of this family and new species of the genus Angiostoma. These nematodes inhabit the lumen of intestine or some glands connected to the intestine of terrestrial mollusks. During field trip of 2007 the nematodes of the genus Angiostoma were discovered in the terrestrial mollusks in the Cat Tien National Park. Unlike the majority of angiostiomatids from European mollusks the nematods from Cat Tien were discovered in a gland associated with pharynx of the host. Numerous juveniles and adult nematodes were observed in the lumen of this gland. Morphology of these nematodes was studied under scanning electron microscope. Cephalic end of these angiostomatids bears acute probolae, directed forward, and encircling oral opening with the crown of projections. Such structures were never reported before for the members of the family Angiostomatidae. Unusual morphology of the cephalic end of these nematodes demonstrate that these latter are 
representatives of, at least, new species of angiostomatids (Fig. 2, D). Sequences of D2D3 expansion segment of LSU rDNA of these nematodes were obtained and analyzed. The nematodes from Cat Tien were found to be a sister group to a clade of European angiostomatids (Fig.3). The clade including all angiostomatids is strongly supported, thus confirming the inclusion of the nematodes from Cat Tien into the family Angiostomatidae.

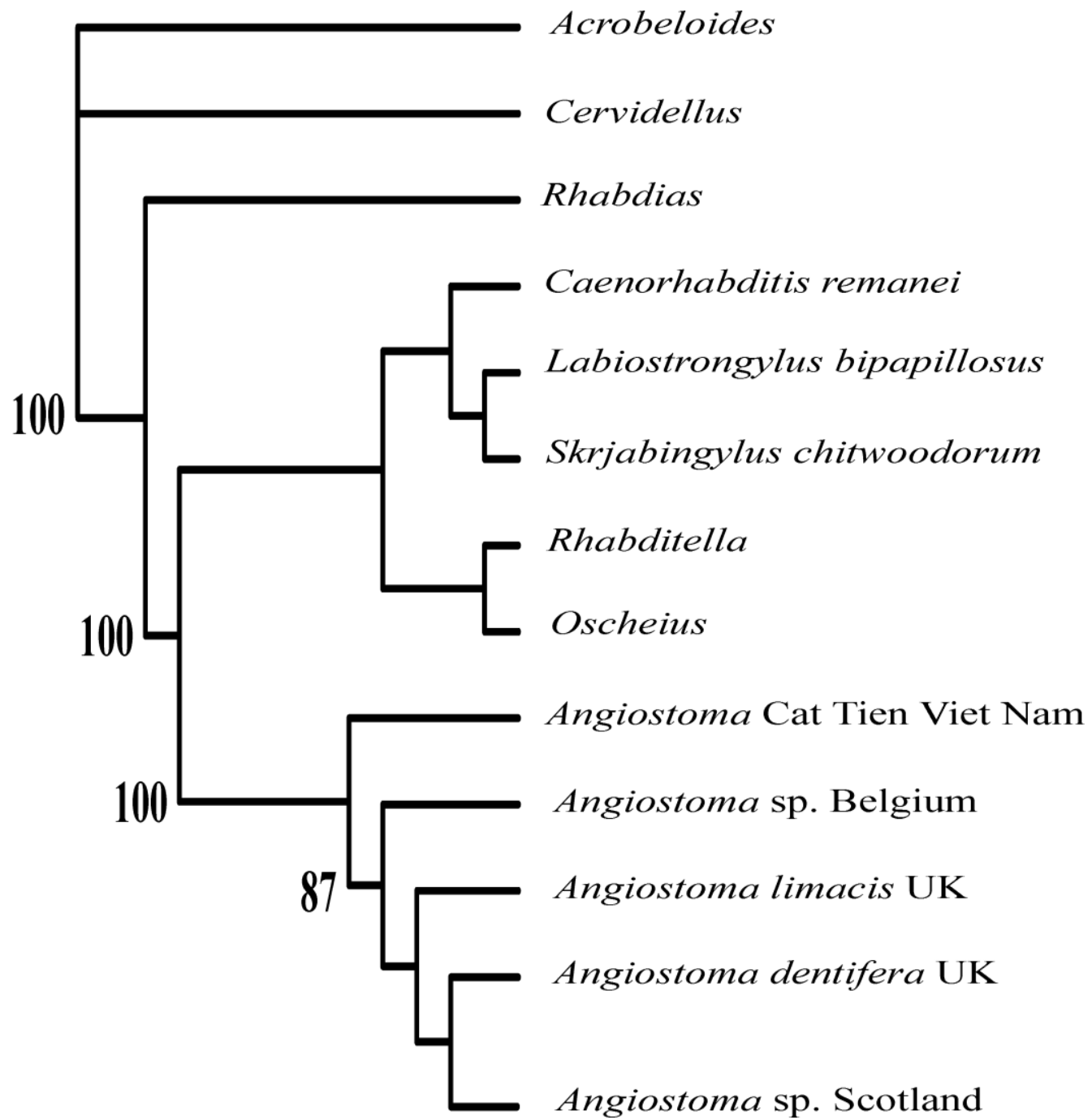

Fig. 2: Phylogenetic tree of relationships of Vietnamese angiostomatid. Phylogenetic tree of relationships of Vietnamese angiostomatid (terrestrial mollusk, Cat Tien National Park) based on the comparison of D2D3 LSU rDNA sequences. The level of bootstrap support is indicated near appropriate nodes. (Optimality criterion = parsimony, 1000 bootstrap replicates, of 772 total characters: 267 characters are constant, 102 variable characters are parsimony-uninformative, 403 parsimony-informative characters). 

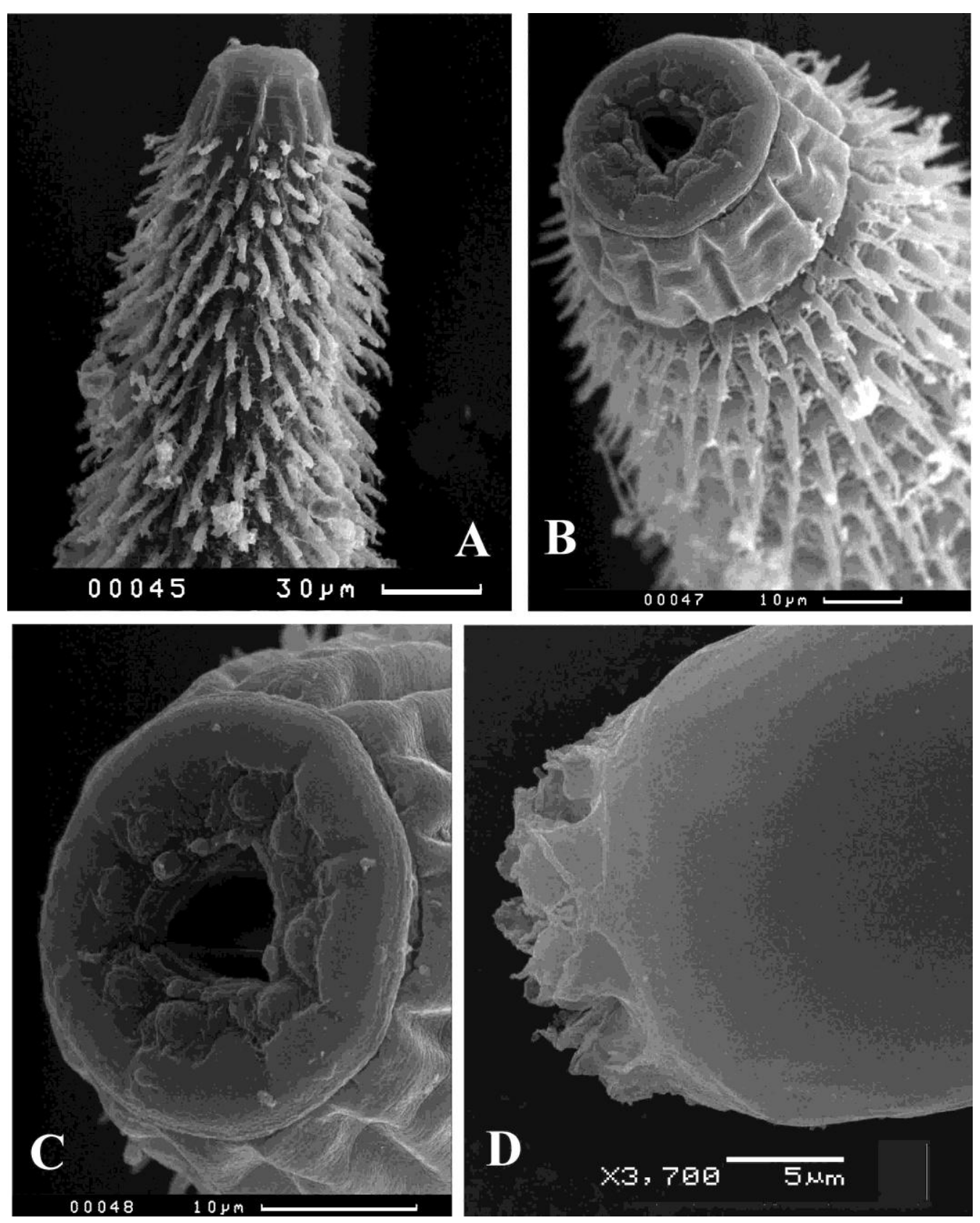

Fig. 3: Thelastomatoidea and Rhabditoidea nematodes from Vietnamese invertebrates. $A-C$ : female of Hystrignathus sp. from intestine of Passalidae beetles, Bidoup-Nui Ba. Aanterior end, lateral view, scale $30 \mu \mathrm{m}, B$ - cephalic end, sublateral view, scale $10 \mu \mathrm{m}$; $C$ - oral opening and cephalic capsule, apical view, scale $10 \mu \mathrm{m} ; \mathrm{D}$ - cephalic end of Angiostoma sp. nematodes from the terrestrial mollusk, Cat Tien, scale $5 \mu \mathrm{m}$. 

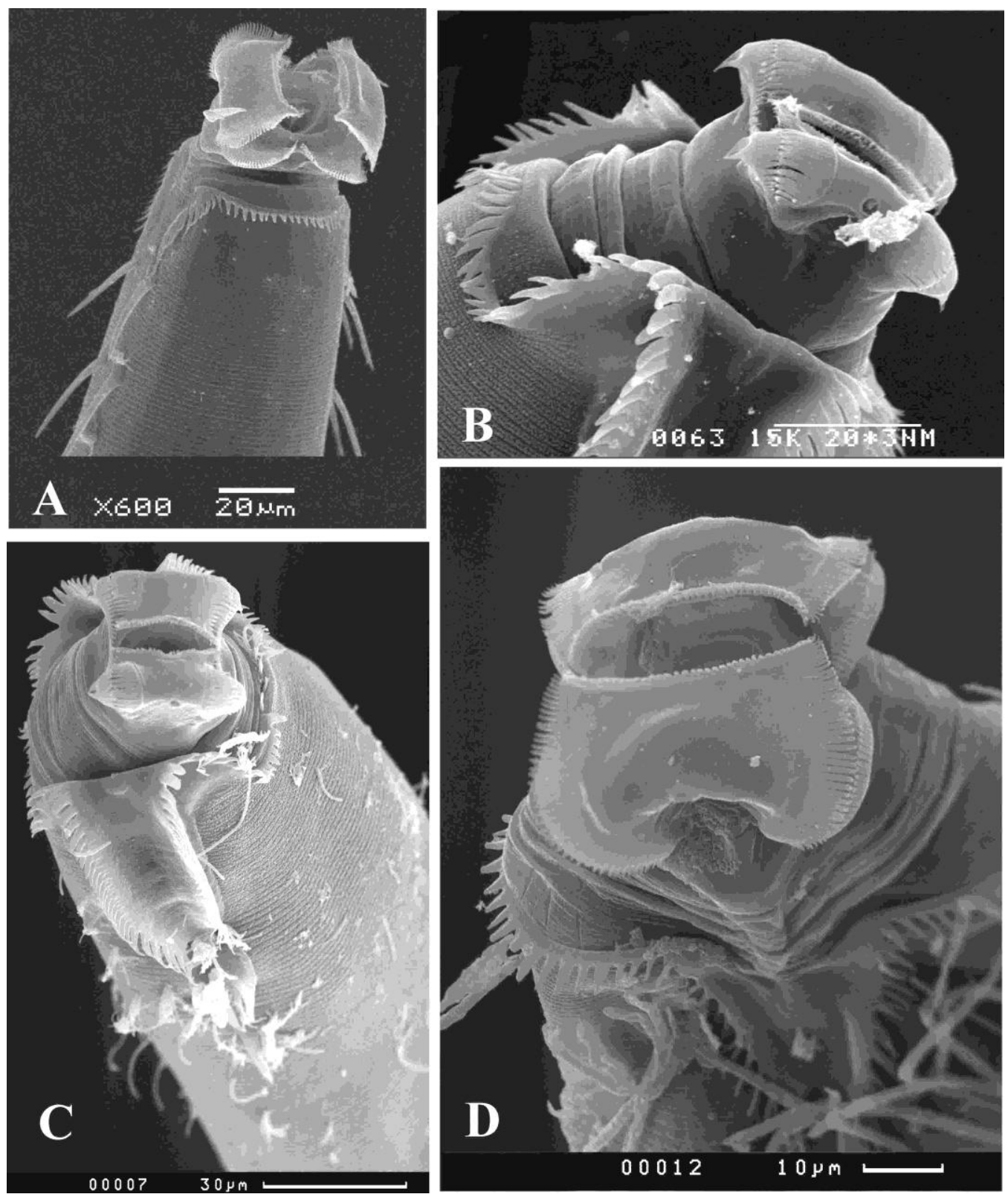

Fig. 4: The nematodes of the genus Heth (Ransomnematoidea) from Vietnamese diplopods. A: head end of female from unidentified spirobolid diplopod, Sin Ho, Lai Chau, ventral view, scale $20 \mu \mathrm{m} ; B-C$ :- female from Plathyracus polydesmid from Cuc Phuong, B head end of lateral view, scale $20 \mu \mathrm{m} ; C$-anterior end, apical view, scale $30 \mu \mathrm{m} ; \mathrm{D}-$ head end of female from spirobolid diplpod collected in Ba Vi, apical view, scale $10 \mu \mathrm{m}$.

\subsection{Studies in nematodes of the superfamily Ransomnematoidea}

The nematodes of this superfamily are inhabiting the lumen of hind gut in tropical diplopods. Until now, these nematodes were not reported from outside of tropical belt. The females of the genus Heth are characterized by the presence of over-developed labia on the anterior end. This 
structure was studied under transmission and scanning electron microscope (Spiridonov, Yushin, 2000). It was show that this cephalic structure in females is responsible for the process of food filtration from host lumen. Its seems hat this unusual apomorpy enabled hethids to spread between different diplopods, and probably was one of the key factors in he speciation inside this group. Numerous species of Heth (type genus of monotypic Hethidae) were described from Americas and Southern Australasia (including Australia, Papua-New Guinea and Indonesian Islands). After first finding of Hethidae in Viet Nam in 1997 during field trip in Cat Tien additional samples were collected in Bac Bo (Ba Vi in 1999, Cu Phuong in 2005, Sin Ho in 2007). Examination of Heth nematodes from different hosts and areas of Viet Nam under scanning electron microscope demonstrate their obvious specific diversity. The size of cephalic labia, the shape of neck collar with spikes and size and distribution spines and sensillae on the surface of female anterior end are clearly different in these samples (Fig. 3, A-D). As fortunate occasion we can consider the fact, that in all collected samples only one morphological type of female was reported from each separate host species. Most probably, it means that in Vietnamese material collected so far, we have no species complexes of Heth nematodes inhabiting the same host, as it was reported for diplopods from Papua New Guinea (Hunt, 1994) or Cuba (Spiridonov.

1989). In the cases when several species of Heth are co-inhabiting the intestinal lumen of the same host specimen it is impossible to identify the correspondence between different morphological types of males and females.

\section{CONCLUSION}

The studies in parasitic nematodes of Vietnamese invertebrates were started many years ago, but were mainly based on the examination of fixed material. The grant support for parasitological studies by the grant from Vietnamese Academy of Science and Technology and Russian Foundation of Basic researches opens possibility of field trips to the little disturbed parts of Vietnamese nature. When nematodes are collected alive it is possible to share found specimens between the needs of traditional morphological study, electron microscopy and molecular taxonomic investigation. These new opportunities are enabling us to obtain rich set of facts to reveal taxonomic links of parasitic forms from Viet Nam and hopefully to reveal the evolutionary patterns of several interesting taxa. Even now, on this intermediate stage, we can see that our knowledge of parasitic nematodes of invertebrates in Viet Nam is far away from saturation. Only with better studied Drilonematoidea we are discovering soon described species, when all newly found nematodes of other superfamilies are new for science. Now we are planning to describe all taxa, which we consider as new for science and follow with our studies of nematode fauna of Viet Nam.

\section{ACKNOWLEDGEMENT}

Authors are grateful to Joint VANY-RFBR commission for the support of these studies with the grant 07-04-90005 Viet_a and to Professors Thai Tran Bai, Anatolii Shileiko and Sergei Golovatch for their help with identification of invertebrate hosts.

\section{REFERENCES}

1. Hunt, D.J. (1994), A synopsis of the Hethidae (Nematoda, RHigonematida) with descriptions of five new species of Heth Cob, 1898 from Papua New Guinea. Russian Journal of Nematology, vol. 2, N1, pp. 15-31. 
2. Ivanova, E.S., Pham Van Luc (2008), Unicorninema montanum gen. et sp. n. (Nematoda, Drilonematoidea) - a parasite of earthworm Amynthas robustus from Viet Nam. Zoologicheskii Zhurnal (I press).

3. Leidy, J. (1850), Description of some nematoid entozoan infesting insects. Proceedings of the Academy of Natural sciences of Philadelphia, vol. 5, N 5, pp. 100-102.

4. Pham Van Luc, S.E. Spiridonov, Wilson M.J. (2005), Aulacnema monodelphis n.g. n.sp. and Angiostoma coloaense n. sp. (Nematoda: Rhabditida: Angiostomatidae) from terrestrial molluscs of Vietnam. Systematic Parasitology, 2005, vol. 60, pp. 91-97.

5. Skrjabin, K.I., Shikhobalova, N.P., and Lagodovskaya, E.A. (1966), Oxyurata of arthropods. Osnovy Nematodologii, vol. 15, Nauka Publishers, Moscow, 538 p. (In Russian).

6. Spiridonov, S.E. (1989), New species of Rhigonematida (Nematoda) from the Cuban spirobolid Rhinocricus sp. (Diplopoda) Folia parasitologica, , vol.36, N 1, pp. 71-82.

7. Spiridonov, S.E., Ivanova, E.S., and Pham Van Luc (2007), Two new species of Ungellidae and Homungellidae (Drilonematoidea, Rhabditida) from Vietnamese earthworms and the phylogenetic links of these families. Russian Journal of Nematology, vol. 15, N 2, pp. 101 108.

8. Spiridonov, S.E. and Yushin V.V. (2000), Ultrastructure of the stoma of Heth mauriesi Adamson, 1982 (Rhigonematida, Hethidae). Nematology, vol. 2, N 4, pp. 417-424. 